\title{
The Humanistic and Economic Burden of Chronic Idiopathic Constipation in the USA: A Systematic Literature Review
}

This article was published in the following Dove Press journal:

Clinical and Experimental Gastroenterology

\author{
Arpita $\mathrm{Nag} \mathbb{D}^{\prime}$ \\ Susan A Martin ${ }^{2}$ \\ Deirdre Mladsi $\mathbb{D}^{3}$ \\ Oyebimpe Olayinka-Amao ${ }^{4}$ \\ Molly Purser ${ }^{5}$ \\ Renu M Vekaria ${ }^{6}$ \\ 'Global Health Economics, Outcomes \\ Research and Epidemiology, Shire, \\ a Takeda Company, Lexington, MA, USA; \\ ${ }^{2}$ Patient-Centered Outcomes \\ Assessment Group, RTI Health Solutions, \\ Ann Arbor, MI, USA; ${ }^{3}$ Health \\ Economics - Strategy and Early Modeling \\ Group, RTI Health Solutions, Durham, \\ NC, USA; ${ }^{4}$ Patient-Centered Outcomes \\ Assessment Group, RTI Health Solutions, \\ Durham, NC, USA; ${ }^{5}$ Health Economics - \\ Regenerative Medicine and Advanced \\ Therapies Group, RTI Health Solutions, \\ Durham, NC, USA; ${ }^{6}$ Value Insight and \\ Access Strategy Group, RTI Health \\ Solutions, Manchester, Lancashire, UK
}

Background: Chronic idiopathic constipation (CIC) is a functional gastrointestinal disorder with an estimated prevalence of $16 \%$ in the USA; however, the humanistic and economic burden of CIC is poorly characterized.

Aim: This systematic literature review aimed to assess the humanistic and economic burden of CIC in adults in the USA.

Methods: Two systematic literature searches of English-language publications on the humanistic and economic burden of CIC in adults in the USA were conducted using electronic databases and other resources. Both searches included the terms "chronic idiopathic constipation" and "functional constipation". Specific terms used in the search on humanistic burden included "quality of life", "SF-36", "SF-12", and "PAC-QOL"; search terms for economic burden included "cost", "resource use", "absenteeism", and "productivity".

Results: Overall, 16 relevant articles were identified. Health-related quality of life (HRQoL) appeared to be reduced in patients with CIC compared with controls and the general US population. Abdominal $(r=0.33-0.49)$, stool $(r=0.23-0.33)$, and rectal symptoms $(r=0.53)$ appeared to be associated with reduced HRQoL. Younger age and female sex were associated with reduced overall HRQoL and greater symptom severity. Direct outpatient costs were higher in patients with CIC than those without CIC (US\$6284 vs US\$5254). Patients with CIC and abdominal symptoms reported more days of disrupted productivity per month than those without abdominal symptoms (3.2 days vs 1.2 days). The overall prevalence of complementary and alternative medicine use by patients with CIC was similar to that in the general US population.

Conclusion: The reduced HRQoL and increased costs associated with CIC indicate unmet therapeutic need in this disorder. Further research is required to better understand the humanistic and economic burden of CIC in the USA.

Keywords: chronic idiopathic constipation, functional constipation, economic burden, health-related quality of life

\section{Plain Language Summary}

People with chronic idiopathic constipation (CIC) have long-term, bothersome constipation that does not have any identifiable cause. Although about $16 \%$ of people in the USA have CIC, little is known about how it affects their quality of life, or about the costs associated with the disease. We searched online databases of published studies to explore what is currently known on these topics. We found that the health-related quality of life - the impact of CIC on physical, mental, emotional and social aspects of life - of people with this disease appears to be worse than in those without CIC. Some symptoms, including stomach pain, straining or pain while passing stools, also appear
Correspondence: Molly Purser Cornwallis Road, P.O. Box 12194 Research Triangle Park, NC 27709, USA

$\mathrm{Tel}+19195416439$

Fax + I 9195417222

Email mpurser@rti.org 
to be associated with worse health-related quality of life in people with CIC. The cost of outpatient care, including visits to doctors, procedures and treatments, appears to be higher for those with CIC than those without, and those with the disease also appear to have a greater number of disrupted days per month at work or school. This suggests a need for better treatments for people with this disease.

\section{Introduction}

Chronic constipation is a common gastrointestinal (GI) disorder with an estimated prevalence of $16 \%$ in the USA. ${ }^{1}$ This disorder mainly affects adults, especially women and those with a lower socio-economic status. ${ }^{1,2}$ Constipation presents a significant economic burden in the USA: the total direct medical costs associated with the disorder were estimated to be US\$235 million in 2001, and $95.3 \%$ of these costs were incurred from outpatient care. ${ }^{3}$ Available data on the direct medical costs associated with chronic constipation are limited; however, it is estimated that $70-90 \%$ of patients with constipation in the USA report bothersome symptoms such as bloating, straining, and hard stool persisting for many years, with a negative impact on health-related quality of life (HRQoL). ${ }^{4,5}$ A large proportion of the costs associated with constipation are therefore likely to be attributable to these patients.

Constipation can be a primary disorder due to dysregulation of neuromuscular tissue in the GI tract, or a secondary disorder resulting from a wide range of conditions, such as neurologic disease or metabolic disorders. ${ }^{6}$ Chronic idiopathic constipation (CIC), or functional constipation (FC), is a primary form of this disorder characterized by symptoms of difficult, infrequent, or incomplete defecation in the absence of any physiological abnormality. ${ }^{1,6,7}$ Unlike other types of constipation, such as those associated with organic causes or induced by opioids or other drugs, the underlying cause of CIC is often poorly understood. In addition, there are no specific tests or biological markers that can be used to diagnose CIC, so diagnosis must be based on clinical symptoms. ${ }^{7}$

The Rome IV criteria are the most common guidelines used by physicians to diagnose CIC. According to these criteria, patients must have at least two of the following symptoms to be diagnosed with this specific disorder: hard or lumpy stools; straining during defecation; a sensation of incomplete evacuation; a sensation of anorectal obstruction or blockage; use of maneuvers to assist defecation; and fewer than three bowel movements per week. ${ }^{6,8}$ Patients must also have insufficient criteria to diagnose inflammatory bowel syndrome with constipation (IBS-C), another form of primary constipation that is more commonly associated with abdominal pain and discomfort than $\mathrm{CIC} .^{6-9}$

Differentiating CIC from other types of constipation can therefore be difficult; however, it is important for managing the disorder effectively, ${ }^{10}$ understanding its impact on HRQoL, and evaluating the specific economic burden of $\mathrm{CIC}$ on patients and healthcare systems. Currently, there is limited information on HRQoL in adult patients with CIC in the USA compared with matched controls or the general US population, and there is also a lack of synthesized data on the economic burden of CIC in the USA, highlighting the need for further research in these areas.

To this end, we performed two systematic literature reviews (SLRs) to: 1) assess the humanistic burden of CIC in adults in the USA, including determinants of HRQoL, such as the type and severity of symptoms, and the validated generic or disease-specific measures used to evaluate HRQoL; and 2) examine the healthcare resource use and direct and indirect costs associated with CIC in the USA.

\section{Methods}

The SLRs to assess the humanistic and economic burden of CIC were conducted according to the guidelines set forth in the Preferred Reporting Items for Systematic Reviews and Meta-Analyses (PRISMA). ${ }^{11}$

\section{Search Terms}

Two separate search strings were designed to identify articles reporting 1) the humanistic and 2) the economic burden of CIC in adult patients ( $\geq 18$ years old) in the USA; these searches were conducted on March 15, 2017 and March 1, 2017, respectively.

For both searches, key search terms used to identify the population of interest were "chronic idiopathic constipation", and "functional constipation". For studies reporting the humanistic burden of CIC, key search terms included "quality of life", "SF-36", "SF-12", and "PAC-QOL"; key search terms for studies reporting the economic burden of CIC included "cost", "resource use", "indirect cost", "absenteeism", and "productivity".

\section{Databases and Other Literature Sources}

Electronic databases (MEDLINE, Embase, the Cochrane Library, and BIOSIS) were searched for relevant Englishlanguage papers published from January 1, 2007 to March 15, 2017 for the search on humanistic burden, and from January 1, 2006 to March 1, 2017 for the search on economic burden. An additional database, the Cumulative 
Index to Nursing and Allied Health Literature, was included in the search on the economic burden of CIC. Both searches were updated on January 12, 2018 to identify any additional relevant publications.

In addition to the two database searches, reference lists from other robust SLRs and meta-analyses were used to identify primary articles. Websites of 2017 congresses (the American College of Gastroenterology Annual Meeting and Digestive Disease Week for both SLRs, and the International Society for Pharmacoeconomics and Outcomes Research for the SLR on the economic burden of CIC) were also searched for relevant abstracts, because these were not indexed on Embase or BIOSIS at the time the searches were conducted. Full details of additional materials used in the searches are provided in Supplementary Table 1.

\section{Identification of Relevant Literature}

The results of both SLRs were screened on two levels: first by title and abstract, and then by full text or final version, according to predefined inclusion and exclusion criteria. When full text or final versions were returned directly from the searches, they were screened at the second level only. After each level of screening, a random selection of $10 \%$ of the publications were reviewed by a second study investigator to avoid potential errors and bias. Key inclusion criteria for both searches were US-based studies of patients with a diagnosis of $\mathrm{CIC}$ or FC who were aged 18 years or older. Key exclusion criteria for both searches were studies in children or animals; non-relevant publication types, such as case reports, letters, or editorials; and publications that did not specifically report studying patients diagnosed with CIC or FC. The Embase and BIOSIS searches returned abstracts from congress proceedings; however, abstracts published before 2015 were excluded, because high-quality abstracts from before 2015 are expected to have since been published in peer-reviewed journals. Data from full-text articles or article abstracts were cited rather than congress abstracts if a full publication on the same data was available. Full details of inclusion and exclusion criteria can be found in Supplementary Table 2.

\section{Results}

\section{The Humanistic Burden of $\mathrm{ClC}$ in Adult Patients in the USA}

In total, 605 records were screened, including 586 records identified via searches of electronic databases and 19 via searches of congress websites and other resources (Figure 1).
Of these, 13 articles met the inclusion criteria of using validated or disease-specific HRQoL measures; details of these studies are presented in Table 1. Of these, nine used the Rome III criteria to define CIC; one used the Rome II criteria; and three studies did not specify the criteria used to define CIC. Overall, 12 studies used the Patient Assessment of Constipation Quality of Life questionnaire (PAC-QOL) to measure HRQoL; three of these studies also used the 12-

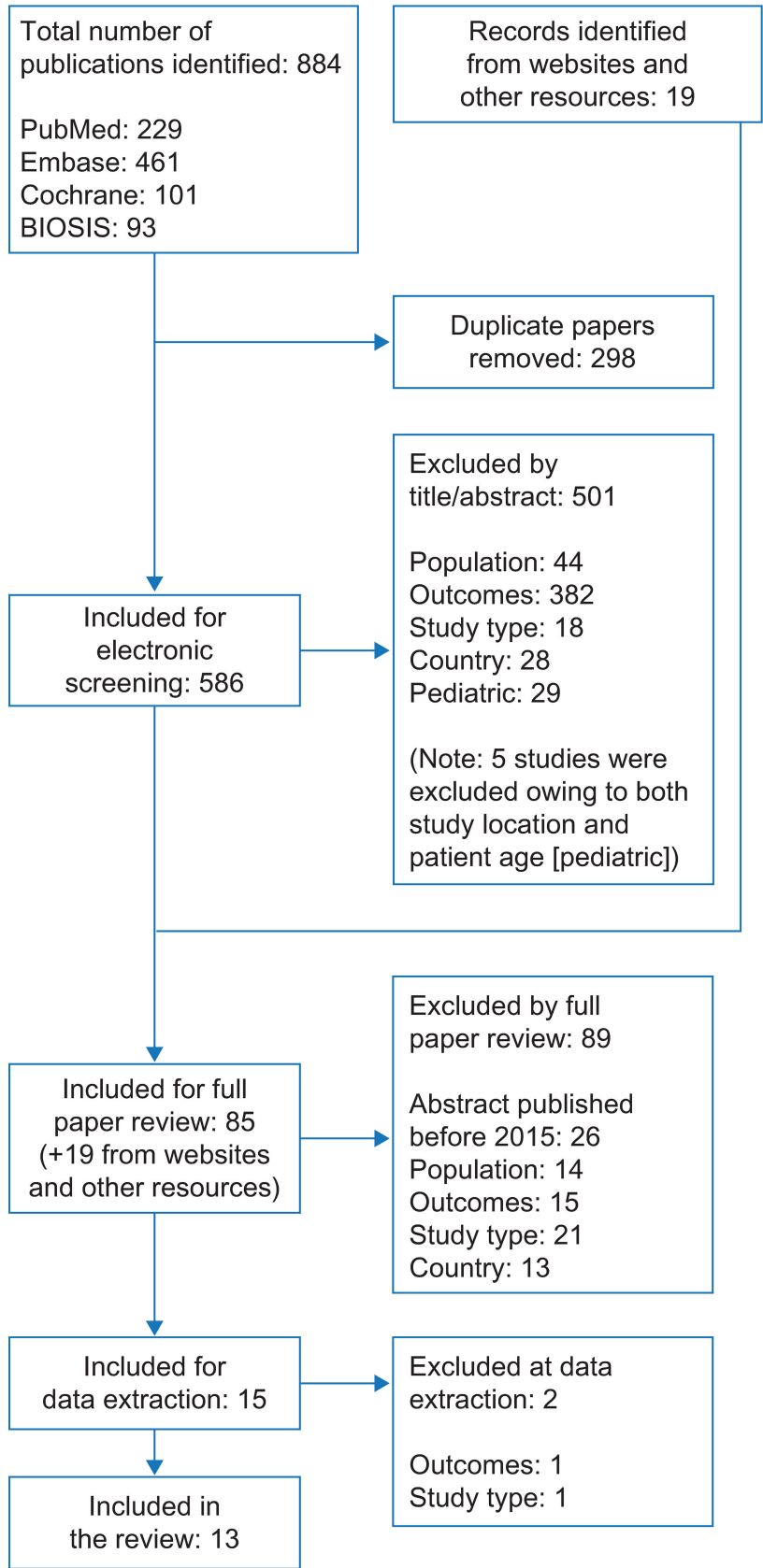

Figure I PRISMA flow diagram of study selection for articles reporting the humanistic burden of $\mathrm{CIC}$ in the USA.

Abbreviations: $\mathrm{ClC}$, chronic idiopathic constipation; PRISMA, Preferred Reporting Items for Systematic Reviews and Meta-Analyses. 
Table I Overview of Studies Included in the SLR on the Humanistic Burden of CIC

\begin{tabular}{|c|c|c|c|c|c|}
\hline Study & Study Type & Objective & $\begin{array}{l}\text { Diagnostic } \\
\text { Criteria for } \mathrm{CICl} \\
\text { FC }\end{array}$ & $\begin{array}{l}\text { HRQoL } \\
\text { Measure }\end{array}$ & $\begin{array}{l}\text { Number of } \\
\text { Patients } \\
\text { with CIC/FC }\end{array}$ \\
\hline $\begin{array}{l}\text { Abel et al, } \\
2017^{15}\end{array}$ & $\begin{array}{l}\text { Longitudinal } \\
\text { observational }\end{array}$ & $\begin{array}{l}\text { To evaluate the differences in demographics, symptoms, } \\
\text { and HRQoL among patients with CIC and IBS-C }\end{array}$ & $\begin{array}{l}\text { Not specified; } \\
\text { diagnosed by } \\
\text { healthcare } \\
\text { provider }\end{array}$ & PAC-QOL & 496 \\
\hline $\begin{array}{l}\text { Abbott et al, } \\
2014^{25}\end{array}$ & $\begin{array}{l}\text { Interventional } \\
(\mathrm{RCT})\end{array}$ & $\begin{array}{l}\text { To evaluate the effect of perineal self-acupressure on } \\
\text { HRQoL and bowel function in patients with } \mathrm{CIC}\end{array}$ & Rome III & $\begin{array}{l}\text { PAC-QOL } \\
\text { SF-I2 }\end{array}$ & 100 \\
\hline $\begin{array}{l}\text { Adragna } \\
\text { et al, } 2016^{26}\end{array}$ & Interventional & To assess the efficacy of OMT in patients with FC & Not specified & $\begin{array}{l}\text { PAC-QOL } \\
\text { SF-I2 }\end{array}$ & 30 \\
\hline $\begin{array}{l}\text { Baker et al, } \\
2016^{27}\end{array}$ & $\begin{array}{l}\text { Retrospective } \\
\text { analysis }\end{array}$ & $\begin{array}{l}\text { To compare PAC-QOL metrics in patients with } \mathrm{CIC} \text { and } \\
\text { dyssynergic defecation }\end{array}$ & Rome III & PAC-QOL & 201 \\
\hline $\begin{array}{l}\text { Body, } \\
2016^{16}\end{array}$ & $\begin{array}{l}\text { Retrospective } \\
\text { analysis }\end{array}$ & $\begin{array}{l}\text { To evaluate the relationship between PAC-QOL and } \\
\text { CTT in patients with diabetes and } \mathrm{CIC}\end{array}$ & Rome III & PAC-QOL & 67 \\
\hline $\begin{array}{l}\text { Chang et al, } \\
2014^{13}\end{array}$ & $\begin{array}{l}\text { Post hoc } \\
\text { analysis of } \\
\text { pooled RCTs }\end{array}$ & $\begin{array}{l}\text { To compare the severity of abdominal and bowel } \\
\text { symptoms in patients with } \mathrm{CIC} \text { treated with linaclotide }\end{array}$ & Rome III & PAC-QOL & $|27|$ \\
\hline $\begin{array}{l}\text { Christie } \\
\text { et al, } 2017^{28}\end{array}$ & $\begin{array}{l}\text { Interventional } \\
(\mathrm{RCT})\end{array}$ & $\begin{array}{l}\text { To assess the efficacy of lubiprostone in patients with } \\
\text { diabetes and } \mathrm{CIC}\end{array}$ & Rome III & PAC-QOL & 76 \\
\hline $\begin{array}{l}\text { Cudmore } \\
\text { et al, } 2017^{29}\end{array}$ & $\begin{array}{l}\text { Interventional } \\
(\mathrm{RCT})\end{array}$ & $\begin{array}{l}\text { To assess the efficacy and safety of psyllium husk fiber } \\
\text { supplement in patients with } \mathrm{CIC}\end{array}$ & Rome III & $\begin{array}{l}\text { PAC-QOL } \\
\text { PAC-SYM }\end{array}$ & 69 \\
\hline $\begin{array}{l}\text { Friedenberg } \\
\text { et al, } 2012^{12}\end{array}$ & $\begin{array}{l}\text { Prospective, } \\
\text { case-controlled }\end{array}$ & $\begin{array}{l}\text { To assess the impact of FC on HRQoL in black } \\
\text { Americans }\end{array}$ & Rome III & SF-36 & 102 \\
\hline $\begin{array}{l}\text { Iturrino } \\
\text { et al, } 2013^{30}\end{array}$ & $\begin{array}{l}\text { Interventional } \\
(\mathrm{RCT})\end{array}$ & $\begin{array}{l}\text { To compare the effect of oral TU-I00 (Tsumura \& Co, } \\
\text { Japan) on various aspects of bowel function in female } \\
\text { patients with } \mathrm{CIC}\end{array}$ & Rome III & PAC-QOL & 45 \\
\hline $\begin{array}{l}\text { Lewicky- } \\
\text { Gaupp et al, } \\
2008^{14}\end{array}$ & Prospective & $\begin{array}{l}\text { To evaluate patient HRQoL before and after treatment } \\
\text { for puborectalis dyssynergia }\end{array}$ & Rome II & $\begin{array}{l}\text { PAC-QOL } \\
\text { PAC-SYM }\end{array}$ & 16 \\
\hline $\begin{array}{l}\text { Nojkov et al, } \\
2017^{17}\end{array}$ & $\begin{array}{l}\text { Retrospective } \\
\text { survey }\end{array}$ & $\begin{array}{l}\text { To examine the effect of sex and age on CIC-related } \\
\text { symptoms and HRQoL }\end{array}$ & Not specified & $\begin{array}{l}\text { PAC-QOL } \\
\text { PAC-SYM }\end{array}$ & 726 \\
\hline $\begin{array}{l}\text { Wong et al, } \\
2010^{31}\end{array}$ & $\begin{array}{l}\text { Secondary } \\
\text { analysis of } \\
\text { prospective } \\
\text { study }\end{array}$ & $\begin{array}{l}\text { To test the hypothesis that FC and IBS-C, as defined by } \\
\text { the Rome III criteria, are not distinct entities }\end{array}$ & Rome III & $\begin{array}{l}\text { PAC-QOL } \\
\text { SF-I2 }\end{array}$ & 231 \\
\hline
\end{tabular}

Abbreviations: $\mathrm{CIC}$, chronic idiopathic constipation; CTT, colonic transit time; FC, functional constipation; HRQoL, health-related quality of life; IBS-C, irritable bowel syndrome with constipation; OMT, osteopathic manipulative treatment; PAC-QOL, Patient Assessment of Constipation Quality of Life questionnaire; PAC-SYM, Patient Assessment of Constipation Symptoms questionnaire; RCT, randomized controlled trial; SF-12, 12-item Short-Form Health Survey; SF-36, 36-item Short-Form Health Survey; SLR, systematic literature review.

item Short-Form Health Survey (SF-12). One study used only the 36-item Short-Form Health Survey (SF-36).

Only one of the 13 articles included normative HRQoL values for the general US population; therefore, this was the only study in which the overall humanistic burden of CIC was assessed. This study used the SF-36 to compare the HRQoL of 102 black Americans with CIC (defined according to the Rome III criteria), aged 40-70 years, with that of age- and sex-matched individuals without CIC, and with the general US population. ${ }^{12}$ The authors found that both the 
physical component summary score and the mental component summary (MCS) score of the SF-36 were significantly lower in patients with CIC than in the control group and the general US population. However, after adjustment for comorbidities, only the MCS score remained significantly lower in patients with CIC than in the control group and the general population. ${ }^{12}$ In addition, after adjustment for comorbidities, the subcomponent scores for bodily pain, vitality, social functioning, and emotional functioning scores were found to be significantly lower for patients with CIC than in the control group (Figure 2). ${ }^{12}$

\section{Determinants of HRQoL in CIC}

Seven studies assessed the correlation between diseaserelated symptoms or specific patient characteristics and HRQoL, as determined by PAC-QOL or SF-12. Four of these studies demonstrated a strong correlation between abdominal and stool symptoms (including abdominal pain, discomfort, bloating, cramps, and distension) and HRQoL.

\section{Abdominal Symptoms}

Three studies indicated that increased severity of abdominal symptoms was associated with reduced HRQoL in patients with CIC. ${ }^{13-15}$ One of these studies, by Chang et al, was a pooled analysis of two randomized controlled trials, including 1271 patients with CIC, defined according to Rome II criteria, and assessed the relationship between symptom severity and HRQoL. The authors found a stronger correlation between abdominal symptoms and baseline PAC-QOL score $(r=0.33-0.49)$ than between bowel symptoms and baseline PAC-QOL score $(r=0.06-0.23)$, irrespective of the level of abdominal pain. This pattern persisted after treatment with linaclotide (abdominal symptoms and PACQOL, $r=0.34-0.62$; bowel symptoms and PAC-QOL, $r=0.21-0.43) .^{13}$

A prospective study by Lewicky-Gaupp et al aimed to assess the effect of physical therapy on symptom severity and HRQoL in 16 patients with CIC, defined according to Rome II criteria, and puborectalis dyssynergia. The authors reported that abdominal symptom severity (as measured using the Patient Assessment of Constipation Symptoms questionnaire [PAC-SYM]) was correlated with the physical discomfort component of the PAC-QOL $(r=0.50, p<0.05){ }^{14}$

In a longitudinal study comparing 852 patients with IBS-C and 496 with CIC, as diagnosed by their healthcare providers, it was reported that abdominal bloating and abdominal distention (as assessed by PAC-SYM) were the most bothersome symptoms, reported by $23.6 \%$ and $21.0 \%$ of patients with CIC, respectively. ${ }^{15}$

Individuals without CIC $(n=100) \quad$ Patients with $\mathrm{CIC}(\mathrm{n}=102)$

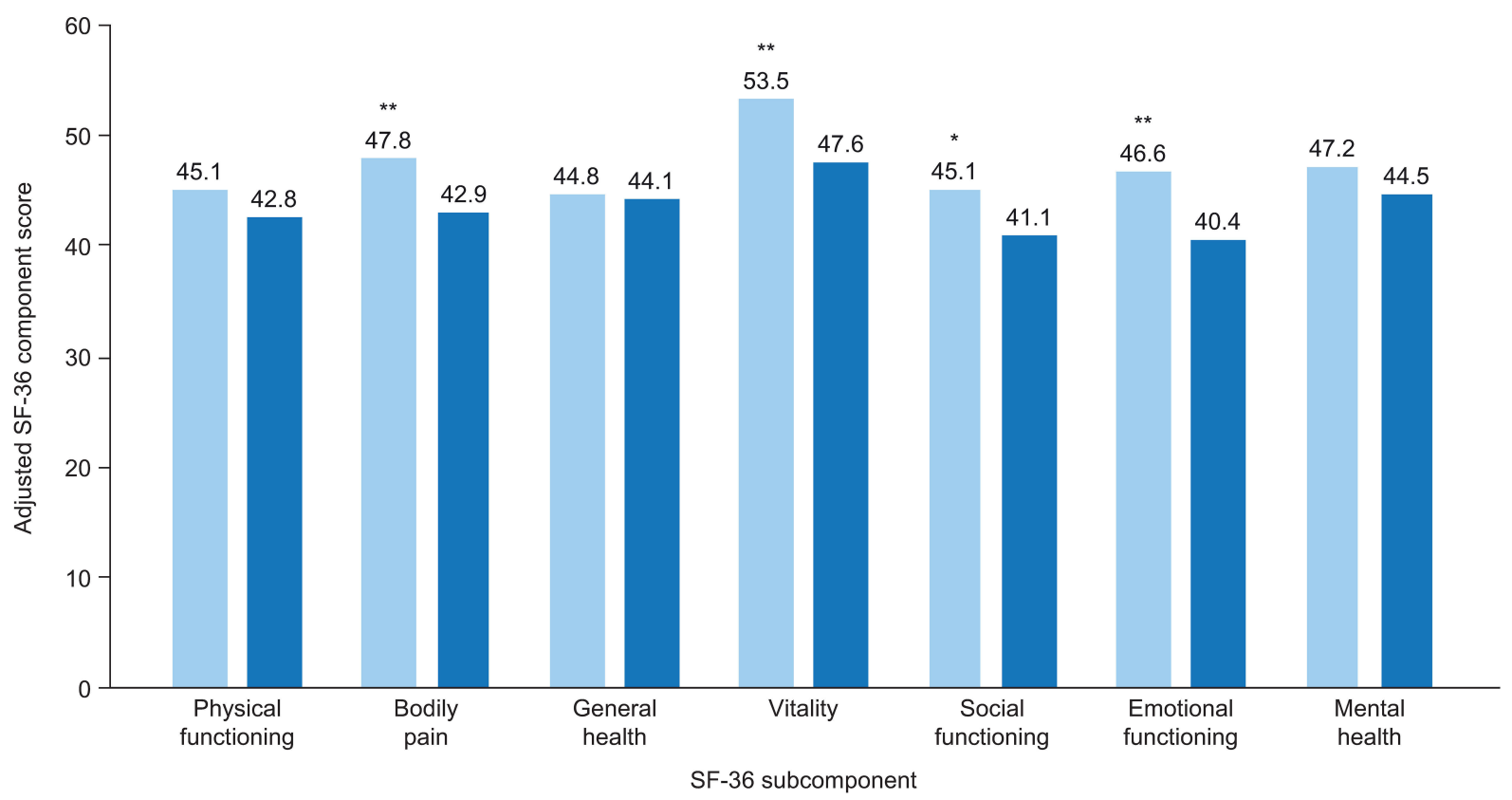

Figure 2 Mean adjusted SF-36 component scores for patients with $\mathrm{CIC}$ and age- and sex-matched individuals without CIC in the USA.

Notes: ${ }^{*} p<0.05, * * p<0.01$ versus patients with $\mathrm{CIC}$. Scores are adjusted for comorbidities. Reprinted by permission from Springer Nature Customer Service Centre $\mathrm{GmbH}$ : Springer Nature, Quality of Life Research, The impact of functional constipation on quality of life of middle-aged black Americans: a prospective case-control study, Friedenberg FK, Dadabhai A, Palit A, Sankineni A, Copyright (c) (20I2). ${ }^{12}$

Abbreviations: $\mathrm{CIC}$, chronic idiopathic constipation; SF-36, 36-item Short-Form Health Survey 
A

PAC-QOL

Satisfaction

Worries and concerns

Psychosocial discomfort

Physical discomfort

PAC-SYM

Stool domain

Rectal domain

Abdominal domain
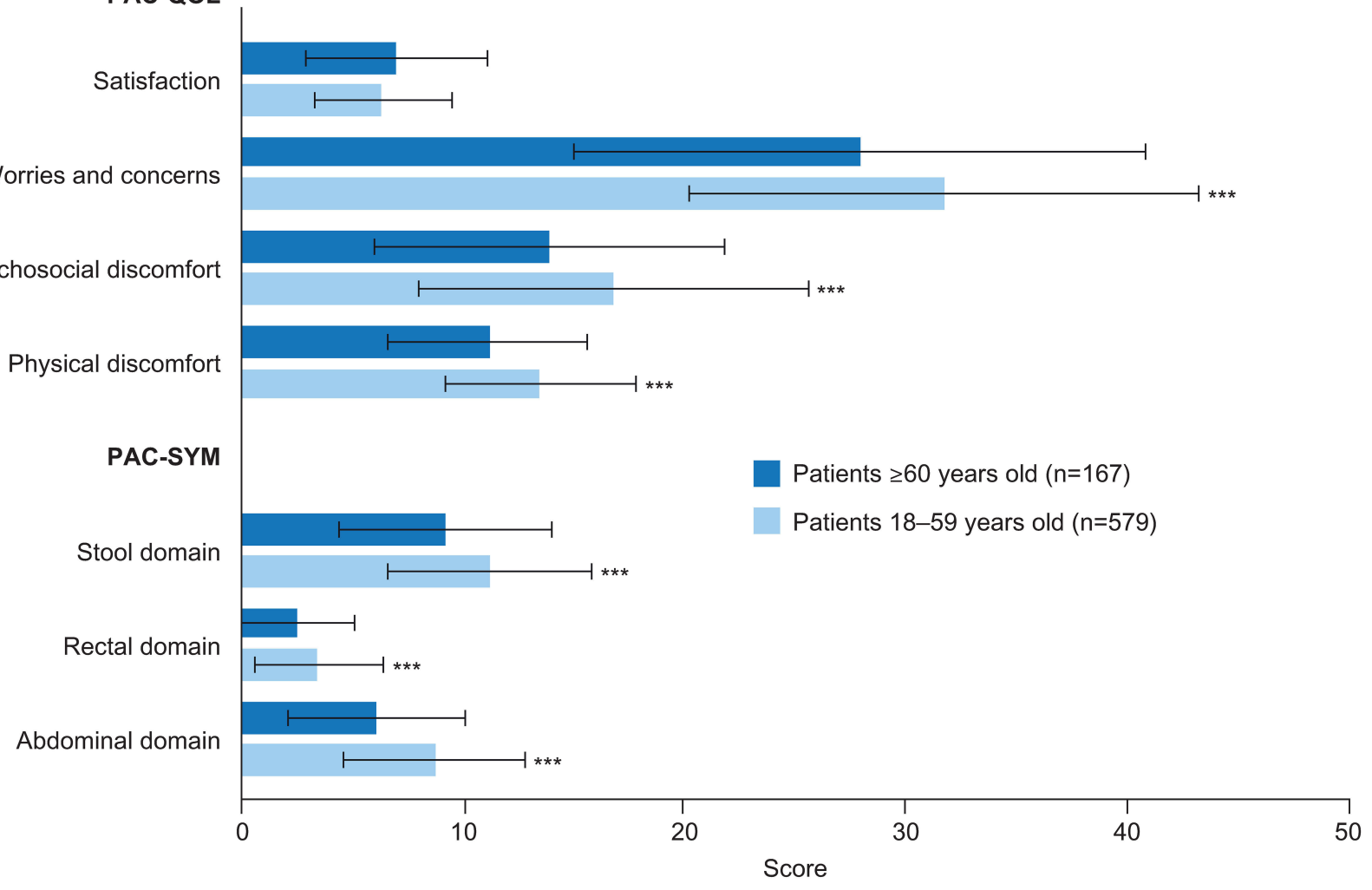

B

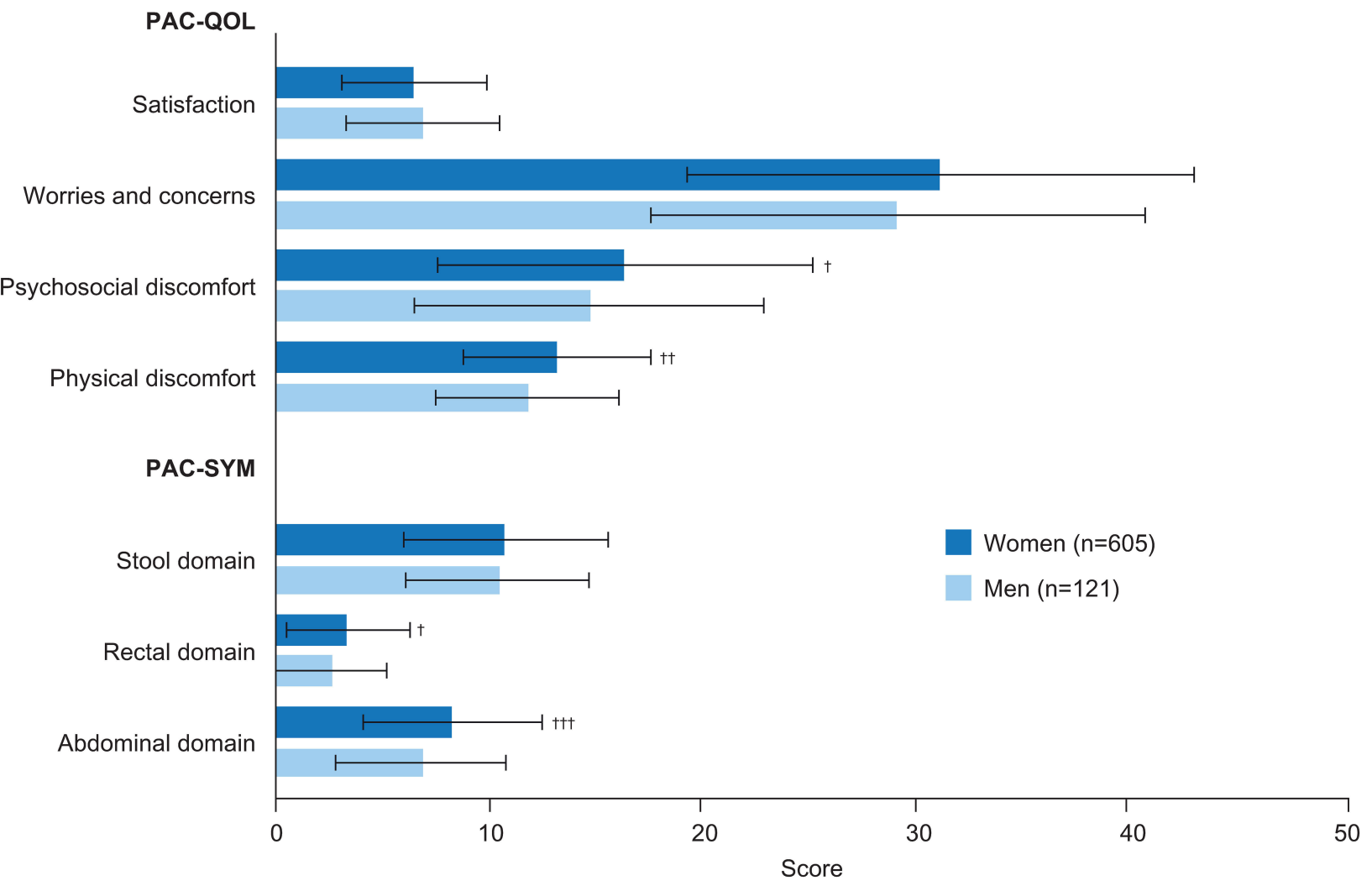

Figure 3 PAC-SYM and PAC-QOL scores in patients with CIC, stratified by $(\mathbf{A})$ age and $(\mathbf{B})$ sex.

Notes: ${ }^{* * *} p<0.001$ versus patients $\geq 60$ years old. ${ }^{\dagger} p<0.05 ;{ }^{\dagger \dagger} p<0.01$; ${ }^{t \dagger \dagger} p<0.00$ I versus men. Data from Nojkov et al. ${ }^{17}$

Abbreviations: CIC, chronic idiopathic constipation; PAC-QOL, Patient Assessment of Constipation Quality of Life questionnaire; PAC-SYM, Patient Assessment of Constipation Symptoms questionnaire. 


\section{Stool Symptoms}

Two interventional studies reported that improvements in stool symptoms (such as straining or incomplete bowel movements) resulted in improvements in overall HRQoL. ${ }^{13,14}$ Chang et al reported that the overall PAC-QOL score correlated with the severity score for straining, both at baseline $(r=0.23-0.33)$ and 12 weeks after treatment with linaclotide $(r=0.34-0.43)$, measured using a five-point ordinal scale $(1=$ not at all; $5=$ an extreme amount). ${ }^{13}$ Lewicky-Gaupp et al reported that improvements in overall HRQoL (measured by PAC-QOL) were significantly correlated with improvements in stool symptoms, measured by PAC-SYM $(r=0.52, p<0.05) .{ }^{14}$ The physical discomfort, worries/concerns, and satisfaction components of the PAC-QOL were all individually correlated with stool symptom improvement $(r=0.65, p<0.005 ; r=0.51$, $p<0.05 ; r=0.53, p<0.05$, respectively). ${ }^{14}$

\section{Rectal Symptoms}

Lewicky-Gaupp et al showed that improvements in rectal symptoms (such as painful bowel movements, burning sensations, and bleeding/tearing) were significantly correlated with the physical discomfort component of the PACQOL $(r=0.53 ; p<0.05)$, but not with overall HRQoL $(r=0.03, p>0.05)$ or any other component of the PACQOL (psychosocial discomfort, $r=0.47$; worries/concerns, $r=0.38$; satisfaction, $r=0.18$, all $p>0.05) .{ }^{14}$

\section{Colonic Transit Time}

One retrospective study of 67 patients with diabetes and CIC defined according to Rome III criteria evaluated colonic transit time (CTT) over a 12-month period, with CTT classified as either delayed $(\geq 59$ hours) or normal $(<59$ hours). ${ }^{16}$ This study did not report a significant correlation between CTT and HRQoL, as measured by the PAC-QOL score; however, only 19 patients had delayed CTT (28.4\%).

\section{Demographic Characteristics}

Only one study, a retrospective analysis of 726 patients with CIC at a single tertiary center, evaluated the association between demographic characteristics (age, sex, race, and body mass index) and HRQoL. The authors reported that younger age and female sex were associated with greater symptom severity (as measured by PAC-SYM) and reduced HRQoL (as measured by PAC-QOL) (Figure 3). ${ }^{17}$

\section{Economic Burden of $\mathrm{CIC}$ in Adult Patients in the USA}

A total of 345 records were identified by the economic burden SLR, including 344 from searches of electronic databases and one from systematic review reference lists (Figure 4). Of these, 280 were screened and 3 met the inclusion criteria (Table 2). Of these, one used modified Rome II criteria to define CIC; one used Rome III criteria; and one did not specify the criteria used to define CIC. No relevant abstracts were identified from searches of recent congresses.

\section{HCRU and Costs Associated with $\mathrm{CIC}$ in the USA}

All three papers identified from the SLR reported on healthcare resource utilization (HCRU) and costs associated with CIC in the USA.

One study used data from electronic medical records to compare total costs, and those for hospital, inpatient, outpatient, and emergency room visits, between 365 patients

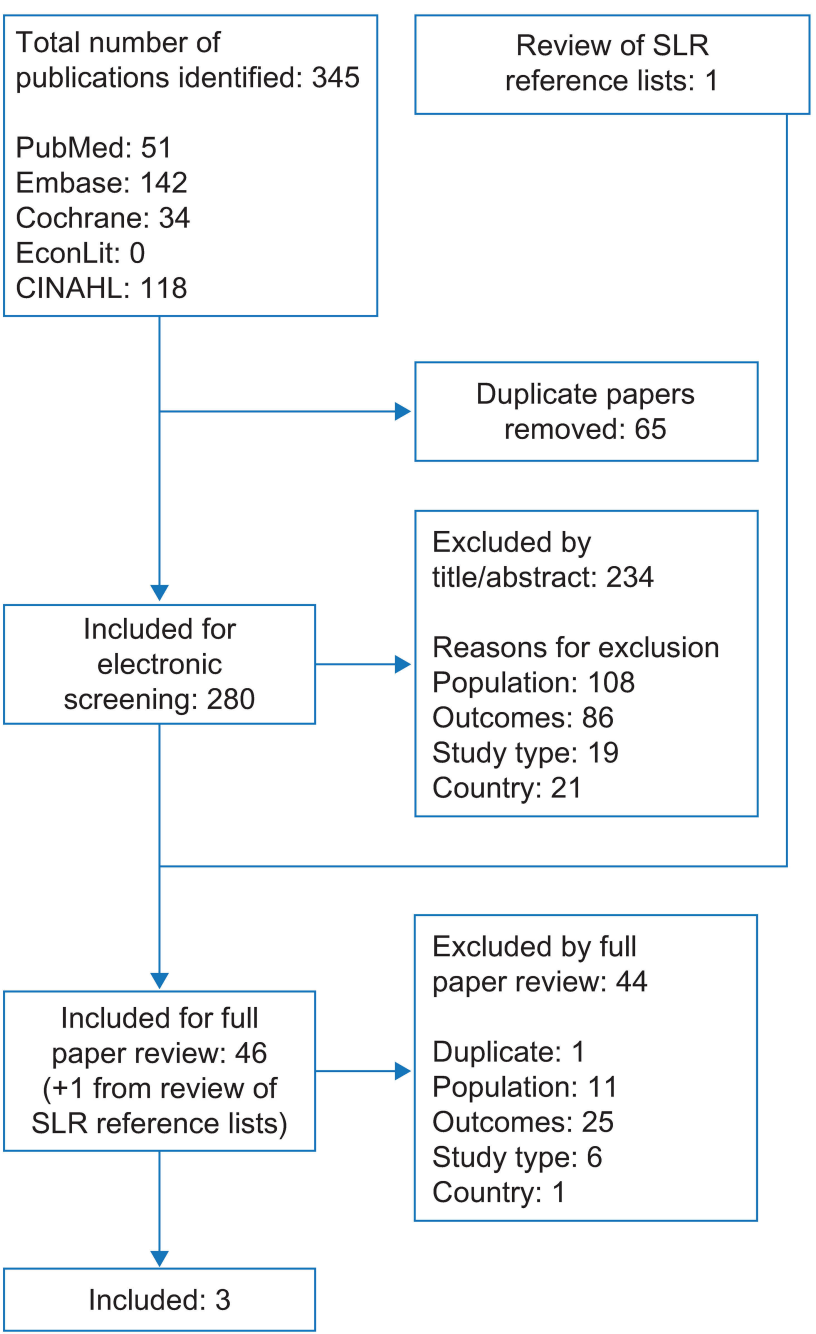

Figure 4 Flow diagram of study selection for articles reporting the economic burden of $\mathrm{CIC}$ in the USA.

Abbreviations: $\mathrm{CIC}$, chronic idiopathic constipation; CINAHL, Cumulative Index of Nursing and Allied Health Literature; SLR, systematic literature review. 
Table 2 Overview of Studies Included in the Economic Burden SLR

\begin{tabular}{|c|c|c|c|c|c|c|c|}
\hline Study & Study Type & $\begin{array}{l}\text { Parameters } \\
\text { Investigated }\end{array}$ & Objective & $\begin{array}{l}\text { Diagnostic } \\
\text { Criteria for } \\
\text { CIC/FC }\end{array}$ & $\begin{array}{l}\text { Data } \\
\text { Source(s) }\end{array}$ & $\begin{array}{l}\text { Study } \\
\text { Duration }\end{array}$ & $\begin{array}{l}\text { Number } \\
\text { of } \\
\text { Patients } \\
\text { with } \\
\text { CIC/FC }\end{array}$ \\
\hline $\begin{array}{l}\text { Herrick et al, } \\
2017^{18}\end{array}$ & $\begin{array}{l}\text { Population- } \\
\text { based } \\
\text { retrospective } \\
\text { study }\end{array}$ & $\begin{array}{l}\text { HCRU } \\
\text { Direct costs }\end{array}$ & $\begin{array}{l}\text { To describe HCRU and compare } \\
\text { medical costs for patients with } \\
\mathrm{CIC} \text { and matched controls }\end{array}$ & $\begin{array}{l}\text { Survey based } \\
\text { on modified } \\
\text { Rome II } \\
\text { questions }\end{array}$ & $\begin{array}{l}\text { EMR Patient } \\
\text { survey } \\
\text { Health } \\
\text { insurance fee } \\
\text { schedule }\end{array}$ & $\begin{array}{l}2 \text { years } \\
\text { and } 10 \\
\text { years }\end{array}$ & 365 \\
\hline $\begin{array}{l}\text { Heidelbaugh } \\
\text { et al, } 2015^{19}\end{array}$ & $\begin{array}{l}\text { Population- } \\
\text { based cross- } \\
\text { sectional } \\
\text { survey }\end{array}$ & $\begin{array}{l}\text { HCRU } \\
\text { Direct costs }\end{array}$ & $\begin{array}{l}\text { To characterize symptom and } \\
\text { disease burden in patients with } \\
\mathrm{CIC} \text { with or without abdominal } \\
\text { symptoms }\end{array}$ & Rome III & Patient survey & I year & 552 \\
\hline $\begin{array}{l}\text { Van Tilburg } \\
\text { et al, } 2008^{20}\end{array}$ & $\begin{array}{l}\text { Prospective } \\
\text { survey }\end{array}$ & $\begin{array}{l}\text { HCRU } \\
\text { Indirect costs }\end{array}$ & $\begin{array}{l}\text { To determine the prevalence, } \\
\text { types, and costs of CAM in } \\
\text { patients with } \mathrm{CIC}\end{array}$ & $\begin{array}{l}\text { Not } \\
\text { specified; } \\
\text { diagnosed by } \\
\text { healthcare } \\
\text { provider }\end{array}$ & $\begin{array}{l}\text { EMR Patient } \\
\text { survey } \\
\text { Administrative } \\
\text { claims at HMO }\end{array}$ & 6 months & 159 \\
\hline
\end{tabular}

Abbreviations: CAM, complementary and alternative medicine; $\mathrm{CIC}$, chronic idiopathic constipation; EMR, electronic medical records; FC, functional constipation; HCRU, healthcare resource utilization; HMO, health maintenance organization; SLR, systematic literature review.

with CIC (assessed using a symptom survey consisting of modified Rome II questions) and age- and sex-matched individuals without CIC over time frames of 2 and 10 years. ${ }^{18}$ No significant differences in total costs were found between the groups; however, outpatient costs were significantly higher over 2 years in patients with CIC than in individuals without CIC (US\$6284 vs US $\$ 5254$, respectively; $p<0.05$ ) (Figure 5). This difference in outpatient costs was not statistically significant at 10 years (US $\$ 25,125$ vs US $\$ 23,240$, respectively; $p>0.05$ ). ${ }^{18}$

Results from a cross-sectional survey that assessed symptoms, care-seeking, and disease burden in 552 patients with CIC defined according to the Rome III criteria showed that patients with CIC and abdominal symptoms experienced a significantly higher number of days per month of disrupted productivity than patients with CIC but no abdominal symptoms ( 3.2 days vs 1.2 days, respectively, $p<0.001) .{ }^{19}$

The third study reported findings from a prospective study of the costs associated with the use of complementary and alternative medicines (CAM) by 159 patients with CIC, as diagnosed by their healthcare providers. The most expensive CAM identified was acupuncture, with a median (range) annual cost of US\$400 (US\$200-400). ${ }^{20}$ The most frequently used CAM was ginger/root tea, which was used by $16.4 \%$ of patients with CIC $(n=26 / 159)$ over a 3-month period. ${ }^{20}$ Massage therapy $(10.7 \%, \mathrm{n}=17 / 159)$, senna tea $(8.2 \%, 13 / 159)$, and yoga $(6.9 \%, 11 / 159)$ were also used more frequently than other CAMs in patients with CIC. However, the overall prevalence of CAM use by patients with CIC in this study was similar to that in the general US population. $^{20}$

\section{Discussion}

The studies identified by this systematic review indicate that patients with CIC in the USA have reduced HRQoL and higher HCRU and direct outpatient costs than individuals without CIC.

In patients with CIC in the USA, HRQoL appears to be lower than that of the overall US population, specifically with regard to the mental components of HRQoL. ${ }^{12}$ This is supported by a multinational survey by Wald et al, which assessed HRQoL (using the SF-36) in 2870 middle-aged individuals with and without constipation, across different social and demographic groups. The reduction in HRQoL reported in this survey was similar to that of patients with other chronic illnesses, including diabetes, heart disease, and depression. ${ }^{21}$

Studies that evaluated the humanistic burden of CIC in this literature review also reported a significant correlation between symptom severity and PAC-QOL scores. ${ }^{13-15}$ One study reported that an increase in the severity of symptoms, 


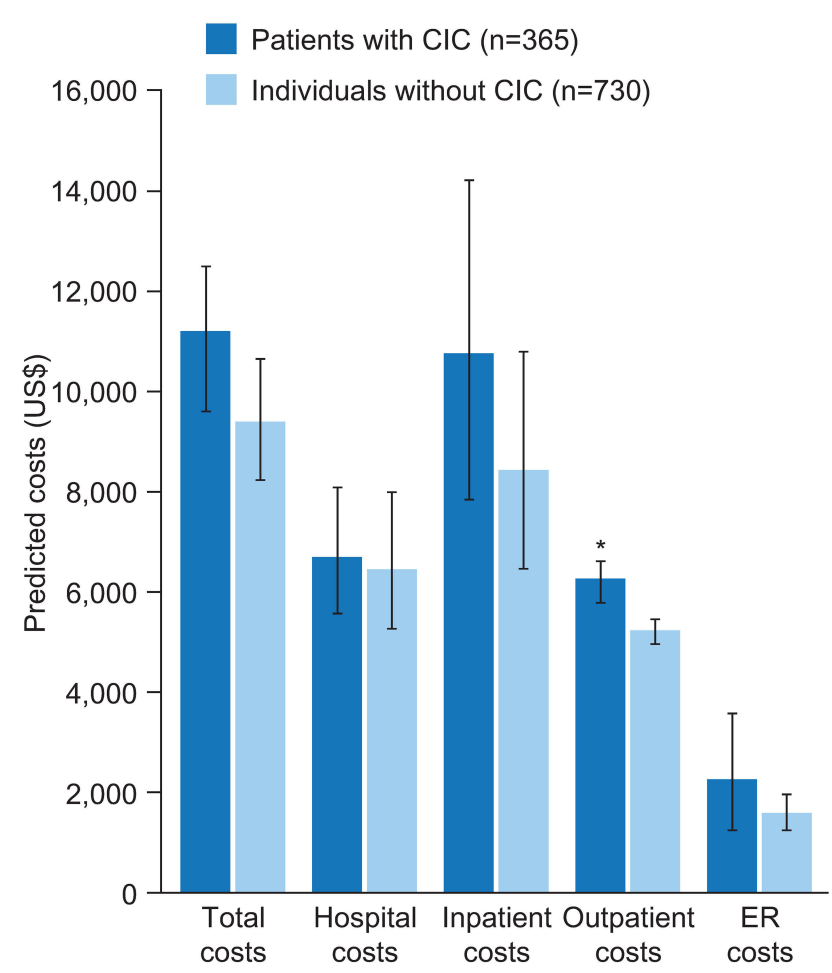

Figure 5 Mean predicted costs (2007-2008) for patients with CIC and age- and sex-matched controls.

Notes: ${ }^{*} p<0.05$. Data from Herrick et al. ${ }^{18}$

Abbreviations: $\mathrm{CIC}$, chronic idiopathic constipation; ER, emergency room.

such as abdominal pain, discomfort, bloating, cramps, distension, straining, or incomplete bowel movements (as measured by PAC-SYM), was associated with reduced HRQoL (as measured by PAC-QOL). ${ }^{14}$ This is supported by the results of another integrated analysis of three Phase III clinical trials in patients with chronic constipation treated with prucalopride, which found a correlation between improvement in PAC-SYM and PAC-QOL scores. ${ }^{22}$

Female sex and younger age (18-59 years) also appear to be associated with reduced HRQoL in patients with $\mathrm{CIC}^{17}$ These findings vary slightly from those reported in the multinational survey by Wald et al, which demonstrated that reduced HRQoL appeared to be significantly associated with female sex and older age ( 60 years or older). ${ }^{21}$

Studies identified in this review that evaluated the economic burden of CIC in the USA reported that patients with CIC have higher direct outpatient costs than individuals without CIC, and may incur substantial additional costs from CAM, such as acupuncture. ${ }^{18,20}$ These findings are supported by a retrospective claims analysis of patients with chronic constipation, which reported that the frequent use of medical services (eg, outpatient services, inpatient hospitalizations, and prescriptions) among these patients resulted in higher direct healthcare costs (US\$9012 per year in 2010) than in matched controls (US\$5504 per year in 2010, $p<0.01$ ). ${ }^{23}$

This systematic review also found that productivity in patients with CIC appears to be affected by the severity of CIC-related symptoms: patients with CIC who had abdominal symptoms reported lower productivity and missed school or work more frequently than those with CIC but no abdominal symptoms. ${ }^{19}$ This is supported by a recent analysis of a national-level survey, which reported that work impairment and absenteeism were higher in patients with chronic constipation than in matched controls (work impairment, $33.7 \%$ vs $21.6 \%$; absenteeism, $9.1 \%$ vs $5.2 \%$, both $p<0.01) .{ }^{24}$

\section{Strengths and Limitations}

A key strength of this systematic review is that it is the first, to our knowledge, to explore the humanistic and economic burden in patients with a specific diagnosis of CIC. However, the strict inclusion and exclusion criteria needed to achieve this mean that some relevant studies that did not indicate a diagnosis of CIC or FC may not have been identified.

Only a small number of articles met the inclusion criteria and a limited number of these contained data relevant to the objectives of this review, which makes it difficult to draw firm conclusions on the humanistic and economic burden of CIC in the USA. In addition, many of the articles reported findings from small patient populations, and these data could not be pooled owing to variability in the types of analyses performed. It is therefore unclear whether these findings are applicable to larger populations.

\section{Conclusions}

Available data indicate that patients with CIC in the USA have reduced HRQoL, and higher HCRU and direct costs compared with those without CIC. In addition, the economic burden of CIC and its impact on HRQoL highlighted in this review suggest a need for more treatment options for patients. Further research is required to better understand the humanistic and economic burden associated with CIC in the USA.

\section{Abbreviations}

CAM, complementary and alternative medicines; CIC, chronic idiopathic constipation; CTT, colonic transit time; EMR, electronic medical records; ER, emergency room; FC, functional constipation; GI, gastrointestinal; 
HCRU, healthcare resource utilization; HMO, health maintenance organization; HRQoL, health-related quality of life; IBS-C, inflammatory bowel syndrome with constipation; MCS, mental component summary; NHP, Nottingham Health Profile; OMT, osteopathic manipulative treatment; PAC-QOL, Patient Assessment of Constipation Quality of Life questionnaire; PAC-SYM, Patient Assessment of Constipation Symptoms questionnaire; RCT, randomized controlled trial; SF-12, 12-item Short-Form Health Survey; SF-36, 36-item Short-Form Health Survey; SLR, systematic literature review.

\section{Acknowledgments}

Medical writing support was provided by Emma Saxon $\mathrm{PhD}$ of PharmaGenesis London, London, UK, with funding from Shire, a member of the Takeda group of companies. An abstract presenting the economic burden of chronic idiopathic constipation was presented at the Digestive Disease Week 2018 and at the Academy of Managed Care Pharmacy 2019 as poster presentations. These abstracts were published in Gastroenterology: [https://doi.org/10.1016/S0016-5085(18) 32625-8] and Journal of Managed Care \& Specialty Pharmacy: [https://doi.org/10.18553/jmcp.2019.25.3-a.s1], respectively. In addition, an abstract presenting the healthrelated quality of life of chronic idiopathic constipation was presented at the American College of Gastroenterology 2018 and at the Academy of Managed Care Pharmacy 2019 as poster presentations. These abstracts were published in the American Journal of Gastroenterology: [https://doi.org/10. 1038/s41395-018-0293-3] and Journal of Managed Care \& Specialty Pharmacy: [https://doi.org/10.18553/jmcp.2019.25. 3-a.s1], respectively.

\section{Author Contributions}

All authors contributed to data analysis, drafting and revising the article, gave final approval of the version to be published, and agree to be accountable for all aspects of the work.

\section{Funding}

Funding support for this study was provided by Shire Development LLC (a member of the Takeda group of companies).

\section{Disclosure}

AN is an employee of Shire, a member of the Takeda group of companies and has received stock from Takeda. $\mathrm{SM}$ is an employee of RTI Health Solutions, Ann Arbor,
MI, USA. OO-A, DM, and MP are employees of RTI Health Solutions, Durham, NC, USA. RMV is an employee of RTI Health Solutions, Manchester, UK. RTI Health solutions received financial support from Shire Development LLC, a member of the Takeda group of companies for participation in the study design, data analysis, and data interpretation. The authors report no other conflicts of interest in this work.

\section{References}

1. Sharma A, Rao S. Constipation: pathophysiology and current therapeutic approaches. Handb Exp Pharmacol. 2017;239:59-74.

2. Suares NC, Ford AC. Prevalence of, and risk factors for, chronic idiopathic constipation in the community: systematic review and meta-analysis. Am J Gastroenterol. 2011;106(9):1582. doi:10.1038/ ajg.2011.164

3. Martin BC, Barghout V, Cerulli A. Direct medical costs of constipation in the United States. Manag Care Interface. 2006;19(12):43-49.

4. Johanson JF, Kralstein J. Chronic constipation: a survey of the patient perspective. Aliment Pharmacol Ther. 2007;25(5):599-608. doi:10.1111/j.1365-2036.2006.03238.x

5. Talley NJ, Weaver AL, Zinsmeister AR, Melton LJ 3rd. Onset and disappearance of gastrointestinal symptoms and functional gastrointestinal disorders. Am J Epidemiol. 1992;136(2):165-177. doi:10.1093/ oxfordjournals.aje.a116483

6. Lacy BE, Mearin F, Chang L, et al. Bowel disorders. Gastroenterology. 2016;150:1393-1407. doi:10.1053/j.gastro.2016.02.031

7. Ford AC, Moayyedi P, Lacy BE, et al. American College of Gastroenterology monograph on the management of irritable bowel syndrome and chronic idiopathic constipation. Am J Gastroenterol. 2014;109(Suppl 1):S2-S26. doi:10.1038/ajg.2014.187

8. Simren M, Palsson OS, Whitehead WE. Update on Rome IV criteria for colorectal disorders: implications for clinical practice. Curr Gastroenterol Rep. 2017;19(4):15. doi:10.1007/s11894-017-0554-0

9. Drossman DA, Chang L, Chey WD, Kellow J, Tack J, Whitehead WE, editors. Rome IV: Functional Gastrointestinal Disorders: Disorders of Gut-Brain Interaction. Raleigh, NC, USA: Rome Foundation Inc.; 2016.

10. Rao SS, Meduri K. What is necessary to diagnose constipation? Best Pract Res Clin Gastroenterol. 2011;25(1):127-140. doi:10.1016/j. bpg.2010.11.001

11. Moher D, Liberati A, Tetzlaff J, Altman DG. Preferred reporting items for systematic reviews and meta-analyses: the PRISMA statement. PLoS Med. 2009;6:e1000097. doi:10.1371/journal.pmed.1000097

12. Friedenberg FK, Dadabhai A, Palit A, Sankineni A. The impact of functional constipation on quality of life of middle-aged black Americans: a prospective case-control study. Qual Life Res. 2012;21(10):1713-1717. doi:10.1007/s11136-011-0089-z

13. Chang L, Lembo AJ, Lavins BJ, et al. The impact of abdominal pain on global measures in patients with chronic idiopathic constipation, before and after treatment with linaclotide: a pooled analysis of two randomised, double-blind, placebo-controlled, Phase 3 trials. Aliment Pharmacol Ther. 2014;40(11-12):1302-1312. doi:10.1111/apt.12985

14. Lewicky-Gaupp C, Morgan DM, Chey WD, Muellerleile P, Fenner DE. Successful physical therapy for constipation related to puborectalis dyssynergia improves symptom severity and quality of life. Dis Colon Rectum. 2008;51(11):1686-1691. doi:10.1007/s10350-008-9392-3

15. Abel J, Taylor DC, Doshi JA, et al. Differences in demographic and symptom-related characteristics among patients with irritable bowel syndrome with constipation (IBS-C) and chronic idiopathic constipation (CIC): results from the Contor study. Gastroenterology. 2017;152(5 Suppl 1):S745. doi:10.1016/S0016-5085(17)32587-8 
16. Body C. Comparing quality of life indices in diabetics with constipation and normal or delayed colonic transit. Neurogastroenterol Motil. 2016;28(Suppl 1):35.

17. Nojkov B, Baker J, Lee A, et al. Impact of age and gender to severity of constipation-related symptoms and quality of life indices in patients with chronic idiopathic constipation. Gastroenterology. 2017;152(5):S514-S515. doi:10.1016/S00165085(17)31896-6

18. Herrick LM, Spalding WM, Saito YA, Moriarty J, Schleck C. A case-control comparison of direct healthcare-provider medical costs of chronic idiopathic constipation and irritable bowel syndrome with constipation in a community-based cohort. J Med Econ. 2017;20 (3):273-279. doi:10.1080/13696998.2016.1253584

19. Heidelbaugh JJ, Stelwagon M, Miller SA, Shea EP, Chey WD. The spectrum of constipation-predominant irritable bowel syndrome and chronic idiopathic constipation: US survey assessing symptoms, care seeking, and disease burden. Am J Gastroenterol. 2015;110 (4):580-587. doi:10.1038/ajg.2015.67

20. van Tilburg MA, Palsson OS, Levy RL, et al. Complementary and alternative medicine use and cost in functional bowel disorders: a six month prospective study in a large HMO. BMC Complement Altern Med. 2008;8:46. doi:10.1186/1472-6882-8-46

21. Wald A, Scarpignato C, Kamm MA, et al. The burden of constipation on quality of life: results of a multinational survey. Aliment Pharmacol Ther. 2007;26(2):227-236. doi:10.1111/j.1365-2036.2007.03376.x

22. Tack J, Camilleri M, Dubois D, Vandeplassche L, Joseph A, Kerstens R. Association between health-related quality of life and symptoms in patients with chronic constipation: an integrated analysis of three phase 3 trials of prucalopride. Neurogastroenterol Motil. 2015;27(3):397-405. doi:10.1111/nmo.12505

23. Cai Q, Buono JL, Spalding WM, et al. Healthcare costs among patients with chronic constipation: a retrospective claims analysis in a commercially insured population. $J$ Med Econ. 2014;17 (2):148-158. doi:10.3111/13696998.2013.860375
24. Sun S, Dibonaventura M, Purayidathil FW, Wagner J-S, Dabbous O, Mody R. Impact of chronic constipation on health-related quality of life, work productivity, and healthcare resource use: an analysis of the national health and wellness survey. Dig Dis Sci. 2011;56:2688-2695. doi:10.1007/s10620-011-1639-5

25. Abbott R, Ayres I, Hui E, Hui KK. Effect of perineal self-acupressure on constipation: a randomized controlled trial. J Gen Intern Med. 2015;30(4):434-439. doi:10.1007/s11606-014-3084-6

26. Adragna V, Mansueto G, Persico L, Salzarulo D, Quaranta C. Efficacy of osteopathic manipulative treatment on functional constipation: pilot study outcome research. Dig Liver Dis. 2016;48(2):e189. doi:10.1016/S1590-8658(16)30295-X

27. Baker J, Chey S, Nojkov B, et al. Differences in disease specific quality of life between patients with dyssynergic defecation and chronic idiopathic constipation. Am J Gastroenterol. 2016;111:S243. doi:10.14309/00000434-201610001-00537

28. Christie J, Shroff S, Shahnavaz N, et al. A randomized, double-blind, placebo-controlled trial to examine the effectiveness of lubiprostone on constipation symptoms and colon transit time in diabetic patients. Am J Gastroenterol. 2017;112(2):356-364. doi:10.1038/ajg.2016.531

29. Cudmore S, Doolan A, Lacey S, Shanahan F. A randomised, double-blind, placebo-controlled clinical study: the effects of a synbiotic, Lepicol, in adults with chronic, functional constipation. Int J Food Sci Nutr. 2017;68(3):366-377. doi:10.1080/096374 86.2016.1244661

30. Iturrino J, Camilleri M, Wong BS, Linker Nord SJ, Burton D, Zinsmeister AR. Randomised clinical trial: the effects of daikenchuto, TU-100, on gastrointestinal and colonic transit, anorectal and bowel function in female patients with functional constipation. Aliment Pharmacol Ther. 2013;37(8):776-785. doi:10.1111/apt.12264

31. Wong RK, Palsson OS, Turner MJ, et al. Inability of the Rome III criteria to distinguish functional constipation from constipation-subtype irritable bowel syndrome. Am J Gastroenterol. 2010;105(10):2228-2234. doi:10.1038/ajg.2010.200
Clinical and Experimental Gastroenterology

\section{Publish your work in this journal}

Clinical and Experimental Gastroenterology is an international, peerreviewed, open access, online journal publishing original research, reports, editorials, reviews and commentaries on all aspects of gastroenterology in the clinic and laboratory. This journal is indexed on American Chemical Society's Chemical Abstracts Service (CAS)

\section{Dovepress}

The manuscript management system is completely online and includes a very quick and fair peer-review system, which is all easy to use. Visit http://www.dovepress.com/testimonials.php to read real quotes from published authors. 